Author version: J. Geophys. Res. (B: Solid Earth), vol.117; 2012; B10305, 13pp.

\title{
SEISMIC CHARACTERIZATION OF HYDRATES IN FAULTED, FINE-GRAINED SEDIMENTS OF KRISHNA-GODAVARI BASIN: FULL WAVEFORM INVERSION
}

P. Jaiswal ${ }^{1^{*}}$, P. Dewangan ${ }^{2}$, T. Ramprasad ${ }^{2}$ and C. A. Zelt ${ }^{3}$

*Email: priyank.jaiswal@okstate.edu, Phone: 405744 6041, Fax: 4053347841

1. Boone Pickens School of Geology, Oklahoma State University, Stillwater, Oklahoma 74078, USA

2. Gas Hydrate Division, CSIR-National Institute of Oceanography, Dona Paula, Goa 403 004, India

3. Department of Earth Science, Rice University, Houston, Texas 77005, USA

Accepted [Date]; received [Date]; in original form [February 3, 2012]

\begin{abstract}
:
In fine-grained, faulted sediments, both stratigraphic and fault-induced structural variations can simultaneously determine the gas hydrate distribution. Insights into hydrate distribution can be obtained from P-wave velocity $\left(\mathrm{V}_{\mathrm{P}}\right)$ and attenuation $\left(\mathrm{Q}_{\mathrm{P}}{ }^{-1}\right)$ character of the gas hydrate stability zone (GHSZ). In this paper, we apply frequency-domain full-waveform inversion (FWI) to surface-towed 2D multichannel seismic data from the Krishna-Godavari (KG) Basin, India, to image the fine-scale (100 X $30 \mathrm{~m}) \mathrm{V}_{\mathrm{P}}$ and $\mathrm{Q}_{\mathrm{P}}{ }^{-1}$ variations within the GHSZ. We validate the inverted $\mathrm{V}_{\mathrm{P}}$ model by reconciling it with a sonic log from a nearby ( $250 \mathrm{~m}$ ) well. The $\mathrm{V}_{\mathrm{P}}$ model shows a patchy distribution of hydrate. Away from the faults-dominated parts of the profile, hydrates demonstrate stratigraphic control which appears to be permeability driven. The $\mathrm{Q}_{\mathrm{P}}{ }^{-1}$ model suggests that attenuation is relatively suppressed in hydratesbearing sediments. Elevated attenuation in non-hydrate-bearing sediments could be driven by the apparent pore-fluid immiscibility at seismic wavelengths. The $\mathrm{V}_{\mathrm{P}}$ and the $\mathrm{Q}_{\mathrm{P}}{ }^{-1}$ models also suggest that fault zones within the GHSZ can be hydrate- or free-gas-rich depending on the relative supply of free gas and water from below the GHSZ.
\end{abstract}

Keywords: KG Basin; gas hydrate; full waveform inversion; P-wave velocity; P-wave attenuation 


\section{INTRODUCTION}

Hydrates can play a potentially significant role in climate change (Gu et al., 2011), seafloor stability (Brown et al., 2006), and energy security (Boswell and Collett, 2011). Gas hydrates detection in offshore continental margins is generally guided by a bottom simulating reflector (BSR); Shipley et al., 1979) which is the most common seismic indicator of the base of the gas hydrate stability zone (GHSZ; Max, 2003). Occasionally, in the presence of faults and fractures, or due to temperature, fluid flux, and salinity changes, the BSR may not be strong or continuous enough to be identified (Cooper and Hart, 2002). An alternative proxy for hydrate detection in such cases could be $P$-wave velocities $\left(V_{P}\right)$. It is common to estimate the $\mathrm{V}_{\mathrm{P}}$ model of a GHSZ using ray-based conventional processing or traveltime inversion (Zillmer, 2006; Zillmer et al., 2005). However, in complex, faulted stratigraphy, limited resolution (order of Fresnel zone) of ray-based methods may not allow the heterogeneous nature of hydrate bearing sediments to be fully reflected in the $V_{\mathrm{P}}$ model.

A high-resolution (order of wavelength) $V_{P}$ model of the GHSZ, which may give insight into the hydrate distribution better than conventional ray-based methods, can be obtained through full waveform inversion (FWI; Huo and Zhang, 2009; Singh et al., 1993). The goal of FWI is to create earth models such that the field data can be closely replicated. FWI can be performed in the time domain, whereby real and simulated traces are compared (Gauthier et al., 1986; Mora, 1987) or in the frequency domain, whereby real and simulated amplitude spectra are compared (Geller and Hara, 1993; Pratt and Worthington, 1990). Virieux and Operto (2009) provide an overview of these methods along with their merits and pitfalls. Gas hydrates have been successfully investigated through both time domain (Pecher et al., 1996; Westbrook et al., 2008) and frequency domain (Delescluse et al., 2011; Xia et al., 2000) methods.

Similar to $\mathrm{V}_{\mathrm{P}}$, P-wave attenuation $\left(\mathrm{Q}_{\mathrm{P}}^{-1}\right)$ is also a valuable rock property helpful for understanding the nature of hydrate distribution (Cordon et al., 2006). While several modeling schematics for relating velocity changes to rock properties are available (Dai et al., 2008; Helgerud et al., 2000), only a few exist for attenuation. Using poroelastic modeling, Gerner et al. (2007) show that when hydrates partially saturate the pore spaces, attenuation increases due to constricted fluid flow. Pecher and Holbrook (2000) suggest that small volumes of hydrates present in the form of cement can increase attenuation, while Rossi et al. (2007), using 3D data from western Svalbard, suggest that cementing hydrates may decrease attenuation. In a laboratory experiment using sand-size sediments, 
Priest et al. (2006) show that attenuation peaks at lower concentrations of cementing hydrate. In another experiment, based on sonic waveforms from the Malik 2L-38 Research Well, Guerin and Goldberg (2002) show that hydrate inclusion can increase attenuation. However, this was later contradicted by Lee (2006), who argued that the sonic waveform's amplitude loss was due to a source-coupling effect. Clearly, mechanisms for attenuation in hydrate-bearing sediments are not well understood.

In geophysical literature, the bulk of laboratory and field studies on hydrate-induced attenuation have been done in coarse-grained (sand-dominated) sediments. Studies in fine-grained (claydominated) sediments are lacking. Bowles (1979) presents a compilation of attenuation in fine-grained sediments. It shows that clay-dominated sediments can attenuate seismic waves even in the absence of hydrates (or free gas). Al-Hunaidi et al. (1996) show that this attenuation in clay dominated soils is due to freezing, which was also in concurrence with findings of Toksoz et al. (1979). Based on these results, Wood et al. (2000) explained that an increase in observed attenuation on the vertical seismic profile (VSPs) from ODP Leg 164 was caused by the freezing of fine mud, and indicated a possibility of hydrates reducing attenuation.

In this paper we use FWI to determine the nature of gas hydrate distribution within fine-grained, clay-dominated, and faulted sediments of the Krishna-Godavari (KG) Basin located offshore of eastern continental margin of India (Figure 1). We apply FWI in the frequency domain. The domain choice is driven by a) efficiency in forward modeling (Marfurt, 1984), and b) the possibility of a multiscale implementation (Sirgue and Pratt, 2004) which mitigates the non-linearity of the inverse problem (Bunks et al., 1995). The seismic data used in this paper are 2D, multichannel, and narrow-aperture (maximum source-receiver offset = target depth). Jaiswal et al. (2012), hereafter referred to as Paper1, used the same dataset, to develop a low-resolution $\mathrm{V}_{\mathrm{P}}$ model though a composite traveltime-inversion depth-migration method. In this paper, by successively inverting $8.4-18.4 \mathrm{~Hz}$ data, we enhance the resolution of the traveltime $\mathrm{V}_{\mathrm{P}}$ model in Paper1 as well as estimate the $\mathrm{Q}_{\mathrm{P}}{ }^{-1}$ model.

While previous studies in the KG basin (Dewangan et al., 2011; Riedel et al., 2010) have linked hydrate distribution to regional faults, we aim to determine whether hydrate distribution also has stratigraphic controls. The crux of our research is development of a high-resolution $\mathrm{V}_{\mathrm{P}}$ and $\mathrm{QP}_{\mathrm{P}}^{-1}$ models that can simultaneously be used for interpretation of relevant stratigraphic features. This paper has the following structure. We first explain the methodology of FWI and then demonstrate its application. We then assess $\mathrm{V}_{\mathrm{P}}$ and attenuation models by checkerboard tests, real and predicted wavefield comparison, 
and comparison with a sonic log from a nearby $(\sim 250 \mathrm{~m})$ well. Finally, we interpret the $\mathrm{V}_{\mathrm{P}}$ and attenuation models with the depth image from Paper1 to gain insight into the hydrate and free-gas system and discuss the desirability of FWI for imaging hydrates in faulted, fine-grained sediments.

\section{METHODOLOGY}

The Pratt (1999) FWI method begins with an initial prediction of the earth model, known as the starting model, and iteratively updates it based on the differences between the predicted and real wavefield, known as the data errors. In this paper the model is parameterized in terms of $\mathrm{V}_{\mathrm{P}}$ and $\mathrm{Q}_{\mathrm{P}}{ }^{-1}$. Model updates in this method are estimated by correlating the back-propagating data residuals with the forward-propagated wavefield (see below). A brief overview of the method is provided here; the reader is guided to the original paper for more details.

The wavefield in the forward problem is computed by solving the wave equation in the frequency domain using the finite-difference mixed-grid approach of Jo et al. (1996). The wave equation used in the Pratt (1999) method automatically accounts for backscattering and wide-angle effects. For an individual angular frequency, $\omega$, the wave equation is expressed as:

$$
\mathbf{d}_{\text {pre }}(\omega)=\mathbf{S}^{-1}(\omega) \mathbf{f}(\omega)
$$

In equation (1), $\mathbf{d}_{\text {pre }}$ is the complex-valued predicted wavefield vector from the model vector $\mathbf{m}, \mathbf{S}$ is a complex valued impedance matrix that contains information about the physical properties of $\mathbf{m}$, and $\mathbf{f}$ is the source term vector. In this paper a 2D acoustic, isotropic approximation of the wave equation is made.

The inverse problem minimizes the $\mathrm{L}_{2}$ norm of the data errors, expressed in an objective function, $E$.

$E(\mathbf{m})=\frac{1}{2} \delta \mathbf{d}^{\mathrm{t}} \delta \mathbf{d}^{*}$

In equation (2), the data errors $\delta \mathbf{d}=\mathbf{d}_{\text {pre }}-\mathbf{d}_{\mathbf{o b s}}$, where $\mathbf{d}_{\mathbf{o b s}}$ is the observed wavefield. In equation (2), $\mathbf{d}$ is a vector comprising the strength of the frequency components obtained by a Fourier transform of the time domain data. The superscript $t$ represents matrix transpose, and the superscript ${ }^{*}$ represents the complex conjugate. The Taylor series expansion and simplification of equation (2) in the neighborhood 
of the model, $\mathbf{m}$, leads to the following relationship in the $k^{\text {th }}$ iteration between the starting, $\mathbf{m}^{\mathrm{k}}$, and the updated, $\mathbf{m}^{\mathrm{k}+1}$, model:

$$
\mathbf{m}^{\mathrm{k}+1}=\mathbf{m}^{\mathrm{k}}-\alpha^{\mathrm{k}} \nabla E^{\mathrm{k}}(\mathbf{m})
$$

In equation (3), $\nabla E(\mathbf{m})$ is the gradient direction and $\alpha$ is the step length that is chosen by a line search method. The key in the Pratt (1999) method is to express the gradient direction as:

$$
\nabla E(\mathbf{m})=\frac{\partial E}{\partial \mathbf{m}}=\operatorname{Real}\left\{\mathbf{F}^{\mathrm{t}}\left[\mathbf{S}^{-1}\right]^{\mathrm{t}} \delta \mathbf{d}^{*}\right\}
$$

In equation (4), $\mathbf{F}$ is known as a virtual source which can be understood as the interaction of the observed wavefield, $\mathbf{d}_{\mathbf{o b s}}$, with the perturbations in the model, $\mathbf{m}$. Individual elements of the virtual source are defined as $\mathbf{f}^{\mathrm{i}}=-\frac{\partial \mathbf{S}}{\partial \mathbf{m}_{\mathrm{i}}} \mathbf{d}_{\mathrm{obs}}$, where $\mathbf{f}^{\mathrm{i}}$ and $\mathbf{m}_{\mathrm{i}}$ are the $i^{\text {th }}$ virtual source and model parameters, respectively. Equation (4) is the mathematical expression of the back-propagated residual wavefield, $\left[\mathbf{S}^{-1}\right] \delta \mathbf{d}$, being correlated with the forward propagated wavefield, $\boldsymbol{F}$. The computational complexity in waveform inversion mainly rests on the computation of $\boldsymbol{S}^{\mathbf{1}}$. For multiple source problems, $\mathbf{S}^{-1}$ is best solved using LU decomposition (Press et al., 1992) and ordering schemes such as nested dissection that take advantage of the sparse nature of $\boldsymbol{S}$ (George and Liu, 1981).

Attenuation in the Pratt (1999) method is mainly a result of absorption, which is a function of material properties such as grain size, mineralogy, fluid saturation, and propagation frequency. Attenuation is included in the inversion by specifying the velocity model (m) as a complex quantity (m $\left.=\mathbf{m}_{\mathbf{r}}+\mathbf{i} \mathbf{m}_{\mathbf{i}}\right)$, where the imaginary $\left(\mathbf{m}_{\mathbf{i}}\right)$ and the real $\left(\mathbf{m}_{\mathbf{r}}\right)$ parts are related through the seismic quality factor $\mathbf{Q}$ (the inverse of attenuation), as:

$$
m_{i}=-\frac{m_{r}}{2 Q}
$$

The stopping criteria in waveform inversion are somewhat qualitative. Waveform inversion seeks a model that can explain as many features of the real wavefield as possible within the range of the wavenumbers being accounted for. In general, for a given frequency (or a group of frequencies), iterations are halted when the objective function (Equation 3) ceases to reduce any further. In the multiscale implementation, the inversion process is halted at a stage where including any higher 
frequencies than present appear to make the model noisy. In the end, a visual assessment of the updated model and its compatibility with the expected stratigraphy, and a comparison of the predicted wavefield to the real wavefield (i.e, their similarity) serve as stopping criteria.

Waveform inversion also requires a source function to compute the model updates. The Pratt (1999) method estimates the source function with the help of the current model. Thus, waveform inversion begins not only with a starting $\mathrm{V}_{\mathrm{P}}$ and $\mathrm{Q}_{\mathrm{P}}{ }^{-1}$ model, but also a starting source signature. For a given data bandwidth, the $\mathrm{V}_{\mathrm{P}}$ and $\mathrm{Q}_{\mathrm{p}}{ }^{-1}$ models are updated using the a priori source signature, following which the source signature is updated using the updated models. As waveform inversion iteratively incorporates higher wavenumbers, higher frequencies are incorporated in the source signature and the resolution of the recovered model is enhanced.

Waveform inversion requires wavenumbers starting from zero to be present in a continuum. The higher end of the wavenumber spectrum is driven by the desired resolution. Wu and Toksoz (1987) demonstrated that inversion of a single frequency covers a finite range of wavenumbers. Following their results, Sirgue and Pratt (2004) demonstrated that inverting a few carefully chosen frequencies is equivalent to inverting all frequencies available in the seismic survey; they referred to the strategy as efficient waveform inversion. Although we do not use the efficient strategy as such, in this paper we use a similar concept while justifying the starting model for waveform inversion, as well as choosing frequencies for inversion.

\section{APPLICATION AND RESULTS}

\subsection{Starting model and data pre-processing}

The key aspect of preparing the data is time windowing of the seismic coda and spatial windowing of the starting model. The end of the time window is set to include transmissions from the deepest part of the starting model. The limiting depth of the starting model in turn is defined as having the wavenumber resolution corresponding to the missing frequencies in the real data. The highest frequency is set in a heuristic manner, depending on the stability of the inversion and the overall proportion of model artifacts to genuine features (somewhat interpretive in nature). The start of the time window is set to exclude noise earlier than the earliest arrival of interest (seafloor reflection in Paper1), and the edges of the time and frequency windows are tapered to avoid ringing. 
The lowest frequency available in the current seismic data is $\sim 8 \mathrm{~Hz}$. Ray-based geometrical approximations with checkerboard tests (Appendix; Jaiswal et al., 2009) suggest that the final $V_{P}$ model from traveltime inversion (Figure 3d; Paper1) has wavenumbers corresponding to $9 \mathrm{~Hz}$ up to at least $\sim 400 \mathrm{~m}$ below the seafloor; this depth is the end of the spatial window for the FWI starting $\mathrm{V}_{\mathrm{P}}$ model. The spatial window includes reflection coda beginning from the seafloor up to the R4 reflector (Figure 4; Paper1). We also found it necessary to replace the coda corresponding to transmission through ocean water with synthetic waveforms for inversion stability.

Time processing for waveform inversion was minimal; it comprised application of a minimum phase bandpass filter of 8-10-20-24 Hz, followed by scaling to account for the non-physical factors source and receiver directivity as well as physical factors such as anisotropy (Brenders and Pratt, 2007). For scaling, the synthetic data were first simulated honoring the real acquisition geometry using the starting model (Figure 2a) and a minimum phase wavelet with a frequency bandwidth similar to the real data. Next, real shot gathers were individually bulk scaled such that the real and predicted amplitudeversus-offset (AVO) variations of the seafloor reflection have the same mean. Less than $5 \%$ of the traces had poor signal-to-noise ratio and were excluded for waveform inversion.

The real data are processed and the individual shot gathers are scaled prior to inversion. As a result, while the traveltimes do not change much, the amplitudes remain reliable only in a relative sense. Thus, while $\mathrm{V}_{\mathrm{P}}^{-1}$ inversion can estimate absolute velocity, the $\mathrm{Q}_{\mathrm{P}}{ }^{-1}$ inversion, which is more sensitive to amplitudes, will yield only a relative change in attenuation. As a result, FWI is performed in two steps. First, only the $V_{P}$ model is updated. To keep the inversion unbiased, attenuation is assumed to be zero.

Next, the final model from the $\mathrm{V}_{\mathrm{P}}$ inversion is used as the starting model for updating the $\mathrm{Q}_{\mathrm{P}}{ }^{-1}$ model. The model above the seafloor is kept unchanged throughout the inversion while updating both $\mathrm{V}_{\mathrm{P}}$ and $\mathrm{Q}_{\mathrm{P}}{ }^{-1}$.

\subsection{Source and $V_{P}$ model update}

FWI began with a determination of the source signature using the starting model and the scaled real data. We have used the Pratt (1999) method to extract the source wavelet. No specific windowing was done for source extraction. Following this, $8.4-18.4 \mathrm{~Hz}$ data were successively inverted in 7 steps (Figure 2). In each step, 3 frequencies spaced $0.4 \mathrm{~Hz}$ apart were inverted simultaneously. The frequency groups were selected by closely monitoring the evolving FWI models. The updated model from each step was used as the starting model for the next step. Prior to updating the model in each step, the source 
signature was recalculated using the updated model from the previous step. While model updates are obtained using limited frequency bandwidth, all frequencies are inverted for the recalculation of the source signature. Iterations were continued in each step until the reduction in the objective function's value was less than $0.1 \%$. Successive incorporation of higher frequencies in each step yielded a higher wavenumber solution of $\mathrm{V}_{\mathrm{P}}$.

Inversion of the lowest frequency group (8.4-9.2 Hz) yields a smooth and coherent model (Figure 2b). As in Paper1, we interpret high $V_{P}(>1.7 \mathrm{~km} / \mathrm{s})$ features within the top $200 \mathrm{~m}$ of the sediment column as hydrate bearing sediments. Successive inversion of higher frequencies localizes these high $V_{P}$ features but also makes it increasingly difficult to distinguish between genuine stratigraphy and model artifacts (Figures $2 \mathrm{~b}$ through g). We lost confidence in our model starting with the inversion of $17.6 \mathrm{~Hz}$ (Figure $2 \mathrm{~g}$ ), as the dimension of model features fell below the highest resolution possible with real data (see Model Assessment). The source updates obtained in each step of inversion were found to be minimal, most likely due to the presence of dominating synthetic transmission coda in the water column that remains unchanged throughout the inversion.

\section{$3.3 Q_{P}^{-1}$ model update}

The final model from $\mathrm{V}_{\mathrm{P}}$ inversion (Figure 2f) was used to estimate $\mathrm{Q}_{\mathrm{P}}{ }^{-1}$. The initial $\mathrm{Q}_{\mathrm{P}}{ }^{-1}$ model is set to imply zero attenuation. Inversion of the lowest frequency group $(8.4-9.2 \mathrm{~Hz})$ yields a smooth $\mathrm{Q}_{\mathrm{P}}{ }^{-1}$ model (Figure 3a). Successive inversion of higher frequencies localizes the $\mathrm{Q}_{\mathrm{P}}{ }^{-1}$ features (Figures $3 \mathrm{~b}$ through f). For consistency, the inversion frequency groups were kept the same as in the $V_{P}$ inversion. As with the $V_{P}$ inversion, we lost confidence staring with the inversion of $17.6 \mathrm{~Hz}$ (Figure 3f), when the evolving $\mathrm{Q}_{\mathrm{P}}{ }^{-1}$ model features became smaller than the highest resolution possible with the real data (see Model Assessment). Both the source and the $\mathrm{V}_{\mathrm{P}}$ are allowed to change simultaneously in each step of $\mathrm{Q}_{\mathrm{P}}{ }^{-1}$ inversion. The $\mathrm{V}_{\mathrm{P}}$ and source updates were minimal, most likely due to the higher sensitivity of amplitudes towards $\mathrm{Q}_{\mathrm{P}}{ }^{-1}$.

\section{4 $V_{P}$ and $Q_{P}^{-1}$ Model Assessment}

The resolution of the final $\mathrm{V}_{\mathrm{P}}$ (Figure $2 \mathrm{f}$ ) and final $\mathrm{Q}_{\mathrm{P}}{ }^{-1}$ (Figure 3e) models is assessed by checkerboard tests (Zelt, 1999). A grid with alternating positive and negative 10\% perturbations is superimposed on the starting model, with the dimensions of individual grids varying from $50-500 \mathrm{~m}$. In individual tests, synthetic data are first simulated honoring the real acquisition using a broad-band (0.2-12 Hz) 
minimum-phase Ricker wavelet. The simulated data are then inverted in a multiscale manner using the same frequencies as for the real data. Results suggest that anomalies with at least $100 \mathrm{~m} \mathrm{X} 30 \mathrm{~m}$ dimensions are reasonably recovered in both the $\mathrm{V}_{\mathrm{P}}$ and the $\mathrm{Q}_{\mathrm{P}}^{-1}$ models (Figures $2 \mathrm{~h}$ and $3 \mathrm{~g}$ respectively), except at the model ends. While the phases of the perturbations are well recovered in both $\mathrm{V}_{\mathrm{P}}$ and $\mathrm{Q}_{\mathrm{P}}{ }^{-1}$ inversions, the $\mathrm{V}_{\mathrm{P}}$ amplitudes are more reliable.

The final model was further assessed both by quantitative and qualitative AVO comparisons. Mismatch in seafloor refection amplitudes between real and simulated data from initial $\mathrm{V}_{\mathrm{P}}$ and initial $\mathrm{Q}_{\mathrm{P}}{ }^{-}$ ${ }^{1}$ (zero attenuation) models, real and simulated data from the final $\mathrm{V}_{\mathrm{P}}$ and initial $\mathrm{Q}_{\mathrm{P}}{ }^{-1}$ models, and real and simulated data from the final $\mathrm{V}_{\mathrm{P}}$ and $\mathrm{Q}_{\mathrm{P}}{ }^{-1}$ models are shown in terms of absolute errors in Figures 4a - c respectively. Minor improvements in the overall seafloor reflection amplitudes from FWI are consistent with the fact that real data were scaled prior to FWI. Mismatch in RMS amplitudes of the entire reflection coda between real and simulated data from initial $\mathrm{V}_{\mathrm{P}}$ and initial $\mathrm{Q}_{\mathrm{P}}{ }^{-1}$ (zero attenuation) models, real and simulated data from the final $\mathrm{V}_{\mathrm{P}}$ and initial $\mathrm{QP}^{-1}$ models, and real and simulated data from the final $V_{P}$ and $Q_{P}^{-1}$ models are shown in terms of absolute errors in Figures $4 \mathrm{~d}-\mathrm{f}$, respectively. Figure 4 suggests that not only does the FWI $V_{P}$ (Figure 2f) better predict the reflection coda than the traveltime $\mathrm{V}_{\mathrm{P}}$, including $\mathrm{Q}_{\mathrm{P}}^{-1}$ (Figure 3e), it further improves data prediction.

A visual comparison of real and simulated data encompassing the projected location of the sites NGHP-01-10 - 13 from traveltime and waveform inversion is shown in Figure 5. A close match (within half-wavelength) in timing of the seafloor reflection (red dashed line; Figure 5) and a deeper reflection (green dashed line; Figure 5) between the real data and the synthetic data simulated from the initial model supports the validity of the starting model. While improvement in data predictions from Figure 5b to Figures $5 \mathrm{c}$ and $d$ support the genuineness of the features in the final FWI $\mathrm{V}_{\mathrm{P}}$ and $\mathrm{Q}_{\mathrm{P}}{ }^{-1}$ models, it also suggests that both FWI $\mathrm{V}_{\mathrm{P}}$ and $\mathrm{Q}_{\mathrm{P}}{ }^{-1}$ do not contribute equally. $\mathrm{V}_{\mathrm{P}}$ affects both arrival times and amplitudes while $\mathrm{Q}_{\mathrm{P}}{ }^{-1}$ affects the amplitudes only. As a result, resolving $\mathrm{V}_{\mathrm{P}}$ improves data prediction significantly more by itself than by additionally incorporating $\mathrm{Q}_{\mathrm{P}}{ }^{-1}$ (Figure 5c vs. d). As a closely related point, incorporating $\mathrm{Q}_{\mathrm{P}}^{-1}$ reduces errors in the far-field (>200m offsets) more than the near-field (Figure 4d), probably because transmissions over longer wavepaths have larger attenuation footprint.

FWI attempts to replicate the entire wavefield with isotropic, visco-elastic approximation. Variability in the real data appearing as irregular trace-to-trace balancing (dashed yellow boxes; Figure 5a) could be due to a combination of elastic and anisotropic effect and acquisition related issues such as 
variable instrument gain, wind motion, cable vibration and marine mammals. While it is not possible to identify and eliminate all phases that are beyond the scope of modeling, careful inversion implementation with optimal choice of frequency groups and bandwidth replicates dominant phases associated with $\mathrm{P}$-wave transmission generating $\mathrm{V}_{\mathrm{P}}$ and $\mathrm{Q}_{\mathrm{P}}{ }^{-1}$ models that are reasonably good description of the subsurface. A comparison of the sonic log from the site NGHP-01-10D with the FWI $V_{P}$ profile at its projection location suggests that the FWI $V_{P}$ trend is closer to the real data compared to time processing or traveltime inversion (Figure 1; inset).

\section{INTERPRETATION}

\subsection{P-wave velocity}

As in Paper1, we interpret $V_{P}$ higher than $1.7 \mathrm{~km} / \mathrm{s}$ within the GHSZ as a proxy for hydrates and velocities lower than $1.4 \mathrm{~km} / \mathrm{s}$ below the GHSZ as a proxy for free gas. Consequently, the final FWI VP model (Figure 2f) suggests that hydrate-bearing sediments have a patchy distribution. This patchy distribution is genuine in that in the FWI $V_{P}$ model, the projected Site NGHP-01-10 is associated with hydrate-bearing sediments, while the projected Site NGHP-01-12 is associated with hydrate-free sediments, which is consistent with the lower volume of hydrates recovered at Site NGHP-01-12 compared to Site NGHP-01-10 (2 \% versus $20 \%$ overall by pore volume). Within the top $20 \mathrm{~m}$ of the seafloor along the model, $\mathrm{V}_{\mathrm{P}}$ is less than $1.5 \mathrm{~km} / \mathrm{s}$. We interpret this as the hydrate-free zone above the sulphate-methane interface (SMI).

A composite of the final $V_{P}$ model (Figure 2f) and depth image from pre-stack migration (Figure 6a) shows that hydrates do not have stratigraphic control except below the bathymetric mound, such as along horizons $\mathrm{H} 1$ and $\mathrm{H} 2$ (Figure 6b). We interpret the high and positive amplitude of horizons H1 and $\mathrm{H} 2$ to be indicative of higher impedance compared to the background. We speculate that $\mathrm{H} 1$ and $\mathrm{H} 2$ are coarser grained horizons (possible diatom blooms) within an otherwise fine background, and therefore preferable for hydrate accumulation (Rempel, 2011). Their high impedance could be due to a more rigid sediment matrix (e.g., silica from diatoms) or due to hydrates.

\subsection{P-wave attenuation}

We compare the $\mathrm{Q}_{\mathrm{P}}{ }^{-1}$ structure with the faults patterns along the seismic line (Figure 6c). The faults patterns are from interpretation of the depth image in Figure 6a. As intuitively expected, our $\mathrm{QP}^{-1}$ model shows high attenuation in the zone with high fault density (vicinity of F2 - F4 zone; Figure 6b). A non- 
intuitive aspect of the $\mathrm{QP}^{-1}$ model, however, is its layered structure which broadly mimics the stratigraphy both above and below the GHSZ (Figure 6). Besides faults, free gas and hydrates are two other features in the study area that can attenuate seismic energy. Free gas is known to increase attenuation (White 1975). The effect of hydrates in fine-grained sediments is, however, less clear. Attenuation along our profile could have a compounded effect from all the three factors. Although decoupling the effect of individual factors from a common $\mathrm{Q}_{\mathrm{P}}^{-1}$ model is non-trivial, it is reasonable to assume that different parts of the $\mathrm{Q}_{\mathrm{P}}{ }^{-1}$ model have more influence from one factor than the other. Consequently, we interpret the $\mathrm{Q}_{\mathrm{P}}{ }^{-1}$ model in a relative sense only.

\subsubsection{Attenuation below the GHSZ}

In general, attenuation is higher below the GHSZ than within it (Figure 6c). This is consistent with the theoretical likelihood of presence of free gas below the GHSZ. The composite of $\mathrm{V}_{\mathrm{P}}$ and $\mathrm{Q}_{\mathrm{P}}{ }^{-1}$ models shows coincident "layers" of high attenuation and low velocity below the GHSZ (Figure 6d). We interpret this as presence of free gas migrating along stratigraphic units that, most likely, have higher permeability than the background. These units continuing into the GHSZ can serve as preferred stratigraphic locations for hydrate precipitation. Presence of free gas within a stratigraphic unit means that it has a higher total fluid conductivity due to lower viscosity of gas compared to water, which can result in enhanced fluid flux through the gas-bearing region (Crutchley et al., 2010). Further, gas migration along a stratigraphic layer depends on the pressure gradient within it, which in turn depends on its geometry. Episodic tectonic movement can create pressure fluctuations within the free gas accumulations below the GHSZ changing flow rates within the stratigraphic units. As a closely related point, for gas to be mobile it also has to exceed a critical saturation to form an interconnected and buoyant column (Schowalter, 1979).

\subsubsection{Attenuation within GHSZ}

Within the GHSZ, away from the fault-dominated parts in the profile, there is a general agreement between high velocity $\left(\mathrm{V}_{\mathrm{P}}>1.7 \mathrm{~km} / \mathrm{s}\right)$ zones indicating hydrate-bearing sediments and zones with low

attenuation (no updates in $\mathrm{Q}_{\mathrm{P}}{ }^{-1}$ from FWI; Figure 6d). We interpret this association to imply that hydrate-bearing sediments are less attenuative than the background sediments. This effect is particularly pronounced along horizons H1 and H2. 
Fault dominated parts of the profile are, in general, associated with elevated attenuation. Below the mound (CMP 600 - 650), a decrease in attenuation is accompanied by a decrease in fault density. Attenuation along F1 has a plume shape. Figure $6 \mathrm{~b}$ also shows that $\mathrm{V}_{\mathrm{P}}$ along $\mathrm{F} 1$ is below the threshold of hydrate-bearing sediments $\left(<1.7 \mathrm{~km} / \mathrm{s}\right.$ ). We interpret elevated attenuation and low $\mathrm{V}_{\mathrm{P}}$ along $\mathrm{F} 1$ to be indicative of fluid and free gas migration within the GHSZ. Our interpretation is in line with other hydrate-bearing basins such as the Blake Ridge (mainly gas driven; Taylor et al., 2000), Hirukangi Margin (mainly fluid driven; Pecher et al., 2010), and Niger Delta (mainly fluid driven; Sultan et al., 2011).

\section{DISCUSSION}

\subsection{Attenuation suppression in hydrate-bearing sediments}

Rossi et al. (2007) and Wood et al. (2000) have reported that hydrates in fine-grained, low-permeability (e.g., clay-dominated) medium can be less attenuative than the background. However, this is in contrast to predominantly reported elevated attenuation in hydrate-bearing sediments in coarse-grained, higher

permeability (e.g., sand-dominated) medium. Attenuation due to hydrates in sand-dominated medium has been explained though mechanisms such as squirt-flow (Chand et al., 2006) and interlayer fluid flow (Gerner et al., 2007). Invocation of these mechanisms requires uniform pore interconnectivity and unrestricted fluid flow. In clay-dominated medium, due to small and spatially variable pore-throat sizes, interconnectivity may be poor and consequently the fluid-flow may be non-uniform.

Attenuation in fine-frained sediments within the GHSZ can be driven by fluid immecibility. Patches of significantly-concentrated free gas (dry zones) adjacent to patches either without or with markedly less-saturated free gas on a mesoscopic scale (much larger than the pore scale, but smaller than the seismic wavelength) can appear as immiscible fluid mixture to the propagating wavefield. The patchiness is however a frequency dependent phenomenon (Quintal et al., 2011). For oil-water and airwater systems, permeability-barrier driven patchy saturation in fine-grained sediments have been experimentally confirmed (Chatenever and Calhoun, 1952) and numerically simulated (Masson and Pride, 2011). Although similar tests for hydrate and free gas systems are lacking, existence of patchy saturation within GHSZ can be easily conceived. Within the GHSZ, occurrence of fully- or partiallysaturated patches surrounded by dry regions can form from a spatially variable fluid flow. Methane from dissociation of hydrates below the GHSZ can re-enter into the HSZ in dissolved or bubble phase. The invading solution will encounter a variable capillary resistance, depending on the sediment micro- 
architecture, and migrate though the path of least resistance. If the path changes with time, e.g., under the influence of temporally-variant sedimentation and deformation, patchy saturation can be created.

In the presence of patchy distribution of fluids, attenuation can result from differential response in pressure changes from differential bulk moduli of immiscible fluids (Muller and Gurevich, 2004; Muller et al. 2010). Seismic compression will cause fluid with the larger bulk modulus to respond with a larger change in fluid pressure, the differential movement leaving residue in the pore space or at grain contacts in turn creating attenuation (Li et al., 2001). Along the profile, we have interpreted possibility of permeability-driven hydrate distribution. Fluid mixing is generally better in higher permeability zones. It is therefore reasonable to assume that in presence of hydrate, the chemistry (saturation, salinity), and therefore the physical properties, of the pore-water will remain relatively uniform. Thus, in a relative sense, hydrate bearing zones can appear more "miscible” than the background and therefore less attenuative.

Dvorkin and Uden (2004) show that if hydrates occur in pore spaces, the host sediments will be attenuative. The result holds for both coarse- and fine-grained medium. Thus, a plausible way of hydrate-bearing sediments to remain relatively non-attenuative is for hydrates to occur in matrix instead of pore spaces. We therefore interpret the dominant form of hydrate to be in a load-bearing state within the background matrix rather than freely floating in the pore spaces. A bank zone along the seismic line (Figure 6) has been attributed to a porosity-proportional distribution of hydrates in Paper1. Figure 6b shows that the seismic blank zone is attenuative. The attenuation could imply presence of fractures (subseismic scale) or hydrates occurring in pore spaces of the sediments as well as the fractures. However, the resolution of the blanked zone is poor (Figure 3g) which limits our interpretational abilities. A rockphysics based investigation may provide further insight.

\subsection{Free gas within the GHSZ}

Attenuation in the GHSZ is contingent upon the presence of partially saturaed zones in the non-hydratebearing sediments. Daigle and Dugan (2011) provide a 1D flow model of methane migration within the GHSZ in context of the southern Hydrate Ridge. They showed that through episodic pressure-driven fracturing, it is possible for the free gas to migrate from below the GHSZ up to the seafloor without forming hydrates and eventually be vented out into the water column. Implied in their model was a) hydraulic fracturing when pore pressure from excess free gas excedes the hydrostatic pressure; and b) an adequately large, deeper gas source with flucturating pore pressure. Alternatively, even in absence of a 
pressure driven mechanism, Liu and Flemings (2006) have showed that it is possible to elevate salinity with hydrate formation such that free gas, water, and hydrate can coexist in the GHSZ. Both of these situations are possible in our case.

Based on the $\mathrm{V}_{\mathrm{P}}$ model, F1 shows the most clear evidence of presence of free gas within the GHSZ (however, this does not exclude presence of free gas elsewhere in the system, which may be below the model resolution). The reduction in $\mathrm{V}_{\mathrm{P}}$ of the sediments along F1 within the GHSZ (Figure 6b) could be either due to absence of hydrate or simultaneous presence of hydrate and free gas. Even if the water advecting along F1 is not excessively saline, gas can still exist in free phase when the supply of gas is in excess with respect to the available water required to form hydrates (Ginsburg and Soloviev, 1997). This stands in contrast to the seismic blank zone which is also underlain by free gas but presumably contains hydrates. We suspect that faults within the blank zone have abundant supply of water from adjacent larger scale faults such as F2, F3 and F4 that penetrate deeper into the subsurface. The difference in water supply along the faults is one possible explanation; the other possibility includes a variable gas flux.

\subsection{General applicability of FWI}

Inversion of a single frequency over a finite range of offsets images a wide range of wavenumbers. Features emerging in a $V_{P}$ model from multiscale FWI are essentially summation of wavenumbers imaged from individual frequency ranges. Even at lowest inversion frequencies, the inverted $V_{P}$ model is expected to contain artifacts. This is due to the presence of random and coherent noise in the data, and the fact that FWI in this paper is an acoustic approximation to an elastic dataset. The artifacts from lower frequency inversion get carried over as a legacy features to the next inversion frequency bandwidth, serving as an incorrect starting model. Additionally, the non-linearity and consequently the non-uniqueness in the frequency-wavenumber relation typically increase with increasing frequency. Thus, if model artifacts are not due to purely random noise that might get self-destructed, it will create cycle-skip and make the inversion increasingly unstable with increasing frequencies. The fidelity of FWI can vary greatly from one dataset to another depending on the variation in signal and noise content from one inversion frequency to another. It is therefore a common practice to choose individual frequency groups as well as the highest frequency for FWI in a heuristic manner. For this dataset, we found that FWI does not yield good results beyond $18.4 \mathrm{~Hz}$. The 8-10-20-24 Hz bandpass filter ensured that frequencies of interest for inversion have adequate strength. 
FWI has at least three advantages over the traveltime inversion method used in Paper1. First, significant gain in vertical resolution is achieved from FWI. For example, the final FWI $V_{P}$ model suggests presence of at least two distinct hydrate-bearing stratigraphic units below the bathymetric high that were not resolved in the final traveltime $\mathrm{V}_{\mathrm{P}}$ model (Figure 3d; Paper1). Although these units are present in the depth image, they could only be interpreted as hydrate bearing using the FWI $\mathrm{V}_{\mathrm{P}}$ model. Second, FWI model estimates the $\mathrm{V}_{\mathrm{P}}$ magnitude more accurately than traveltime inversion as shown by the $\mathrm{V}_{\mathrm{P}}$ comparison in Figure 1 inset. Third, traveltime inversion cannot estimate attenuation. The amplitudes, on the other hand, are sensitive to attenuation, making FWI a necessity for fully understanding the hydrate / free gas system.

In a recent experiment (Delescluse et al., 2011) apply nonlinear acoustic inversion to long offset (9 km long streamer) data from the Scotia margin to image hydrate-bearing sediments within $300 \mathrm{~m}$ of the seafloor in water depths of 1600m. They invert $8-24 \mathrm{~Hz}$ data and achieve $\sim 30 \mathrm{~m}$ vertical resolution. Other researchers such as Cheng et al. (2006), LeBlanca et al. (2007), Petersen et al.(2007), Schnurle et al. (2004) and Wang et al. (2010) also argue in favor of using long-offset data for imaging gas hydrates. Although we do not denounce the benefits of long offset survey, we have shown that high ( 30m) vertical resolution can be obtained with narrow aperture survey (offset $=1.2 \mathrm{X}$ target depth) with FWI. Most of the references cited above which use a local descent method for inversion create their starting models using turning ray tomography from first arrivals in OBS data or stacking velocity analysis of MCS data. Our starting-model-building method includes reflection ray paths from multiple horizons, providing better ray coverage of the tomography model (Paper1). More importantly, the combination of reflection tomography with depth migration ensures that the starting model not only has high wavenumber content but is also kinematically correct. Further, our method for windowing the starting model ensures a continuous wavenumber converge as required by FWI.

\section{CONCLUSIONS}

FWI yielded reliable estimates of $V_{P}$ and attenuation even with an acoustic approximation to elastic data, most likely due to the narrow aperture of the seismic survey which restricts mode conversion. Success of FWI strongly depends on data preconditioning and the starting model. The amount of coda (maximum time starting from the seafloor reflection) used in FWI was limited to what could be initially predicted by the starting model. Criteria used to halt the FWI included the reliability of evolving velocity and attenuation perturbations, similarity of the real and simulated data, and the convergence of 
the objective function. FWI yielded directly-interpretable, fine-scale (100 X $30 \mathrm{~m}$ ) structure of $\mathrm{V}_{\mathrm{P}}$ and $\mathrm{Q}_{\mathrm{P}}{ }^{-1}$. Although depth image from pre-stack migration has higher resolution, FWI models provide complementary information on physical properties. Therefore, a composite of the two is optimal for interpretation of the hydrate and free-gas system.

A combination of $\mathrm{V}_{\mathrm{P}}$ model and the depth image suggests that hydrates distribution has both structural and stratigraphic controls. A combination of $\mathrm{Q}_{\mathrm{P}}{ }^{-1}$ model and fault pattern (from the interpretation of the depth image) suggests that faults enhance attenuation. Similarly, a combination of $\mathrm{V}_{\mathrm{P}}$ and $\mathrm{Q}_{\mathrm{P}}{ }^{-1}$ models suggests that free gas enhances, but hydrates suppress attenuation. Relatively higher attenuation in non-hydrate-bearing sediments could be due to patches of dry, partially and fully saturated sediments appearing as immiscible fluid mixture to the propagating wavefield. The $\mathrm{V}_{\mathrm{P}}$ and the $\mathrm{Q}_{\mathrm{P}}{ }^{-1}$ models also suggest that fault zones can be hydrate or free gas rich depending on relative supply of free gas and water from below the GHSZ.

\section{ACKNOWLEDGEMENTS}

Funding was provided by the US Department of Energy (Award No.: DE-FC26-06NT42960). ONGCL (India) provided the seismic data. Thanks to A. V. Sathe and M. V. Lall for their valuable input in interpretation. Discussions with D. Brenders greatly improved our confidence in the full-waveform inversion results. Thanks to the associate editor, an anonymous reviewer and Gareth Crutchley for their time and effort in improving the quality of this paper.

\section{REFERENCES}

Al-Hunaidi, M.O., Chen, P.A., Rainer, J.H., et al., 1996. Shear moduli and damping in frozen and unfrozen clay by resonant column tests. Canadian Geotechnical Journal 33, 510-514, doi: doi:10.1139/t96-073

Blakeslee, S., Malin, P. and Alvarez, M., 1989. Fault-zone attenuation of high-frequency seismic waves. Geophysical Research Letters, 16, doi: 10.1029/89GL02836.

Boswell, R., Collett, T.S., 2011. Current perspectives on gas hydrate resources. Energy \& Environmental Science 4, doi: 10.1039/C0EE00203H

Bowles, J.E., 1979. Physical and Geotechnical Properties of Soils. McGraw-Hill, Inc., New York. 
Brenders, A.J., Pratt, R.G., 2007. Full waveform tomography for lithospheric imaging: results from a blind test in a realistic crustal model. Geophysical Journal International 168, 133-151, doi: 10.1111/j.1365-246X.2006.03156.x

Brown, H.E., Holbrook, W.S., Hornbach, M.J., et al., 2006. Slide structure and role of gas hydrate at the northern boundary of the Storegga Slide, offshore Norway. Marine Geology 229, 179-186, doi: 10.1016/j.margeo.2006.03.011

Bunks, C., Saleck, F.M., Zaleski, S., et al., 1995. Multiscale seismic waveform inversion. Geophysics 60, 1457-1473, doi: 10.1190/1.1443880

Chand, S., Minshull, T.A., Priest, J.A., et al., 2006. An effective medium inversion algorithm for gas hydrate quantification and its application to laboratory and borehole measurements of gas hydratebearing sediments. Geophysical Journal International 166, 543-552, doi: 10.1111/j.1365246X.2006.03038.x

Cheng, W.B., Lee, C.S., Liu, C.S., et al., 2006. Velocity structure in marine sediments with gas hydrate reflectors in offshore SW Taiwan, from OBS data tomography, Terrestrial Atmospheric and Oceanic Sciences, pp. 739-756.

Cooper, A.K., Hart, P.E., 2002. High-resolution seismic-reflection investigation of the northern Gulf of Mexico gas-hydrate-stability zone. Marine and Petroleum Geology 19, 1275-1293, doi: 10.1016/S02648172(02)00107-1

Cordon, I., Dvorkin, J., Mavko, G., 2006. Seismic reflections of gas hydrate from perturbational forward modeling. Geophysics 71, F165-F171, doi: 10.1190/1.2356909

Crutchley, G.J., Geiger, S., Pecher, I.A., et al., 2010. The potential influence of shallow gas and gas hydrates on sea floor erosion of Rock Garden, an uplifted ridge offshore of New Zealand. Geo-Marine Letters 30, 283-303, doi: 10.1007/s00367-010-0186-y

Dai, J.C., Snyder, F., Gillespie, D., et al., 2008. Exploration for gas hydrates in the deepwater, northern Gulf of Mexico: Part I. A seismic approach based on geologic model, inversion, and rock physics principles. Marine and Petroleum Geology 25, 830-844, doi: 10.1016/j.marpetgeo.2008.02.006

Daigle, H., Dugan, B., 2011. Capillary controls on methane hydrate distribution and fracturing in advective systems. Geochemistry Geophysics Geosystems 12, doi: 10.1029/2010gc003392

Delescluse, M., Nedimovic, M.R., Louden, K.E., 2011. 2D waveform tomography applied to longstreamer MCS data from the Scotian Slope. Geophysics 76, B151-B163, doi: 10.1190/1.3587219

Dewangan, P., Sriram, G., Ramprasad, T., et al., 2011. Fault system and thermal regime in the vicinity of site NGHP-01-10, Krishna-Godavari basin, Bay of Bengal. Marine and Petroleum Geology, doi:10.1016/j.marpetgeo.2011.03.009

Dvorkin, J.P., Uden, R., 2004. Seismic wave attenuation in a methane hydrate reservoir. The Leading Edge 23, 730 - 732, doi:10.1190/1.1786892. 
Gauthier, O., Virieux, J., Tarantola, A., 1986. Two-dimensional nonlinear inversion of seismic waveforms: Numerical results. Geophysics 51, 1387-1403, doi: 10.1190/1.1442188

Geller, R.J., Hara, T., 1993. Two efficient algorithms for iterative linearized inversion of seismic waveform data. Geophysical Journal International 115, 699-710, doi: 10.1111/j.1365246X.1993.tb01488.x

George, A., Liu, J., 1981. Computer Solution of Large Sparse Positive Definite Systems. Prentice Hall, Englewood Cliffs, NJ.

Gerner, A., Saenger, E.H., Shapiro, S.A., 2007. Attenuation of P-waves due to interlayer fluid flow in hydrate-bearing sediments. Journal of Geophysics and Engineering 4, 394-403, doi: 10.1088/17422132/4/4/005

Ginsburg, G.D., Soloviev, V.A., 1997. Methane migration within the submarine gas-hydrate stability zone under deep-water conditions. Marine Geology 137, 49-57, doi: 10.1016/S0025-3227(96)00078-3

Gu, G., Dickens, G.R., Bhatnagar, G., et al., 2011. Abundant Early Palaeogene marine gas hydrates despite warm deep-ocean temperatures. Nature Geosci 4, 848-851, doi: http://www.nature.com/ngeo/journal/v4/n12/abs/ngeo1301.html\#supplementary-information

Guerin, G., Goldberg, D., 2002. Sonic waveform attenuation in gas hydrate-bearing sediments from the Mallik 2L-38 research well, Mackenzie Delta, Canada. J. Geophys. Res. 107, doi: doi:10.1029/2001JB000556

Helgerud, M.B., Dvorkin, J., Nur, A., 2000. Rock physics characterization for gas hydrate reservoirs Elastic properties, in: Holder, G.D., Bishnoi, P.R. (Eds.), Gas Hydrates: Challenges for the Future, pp. 116-125.

Huo, Y.Y., Zhang, M., 2009. Full waveform inversion of gas hydrate reflectors in Northern South China Sea. Acta Geophysica 57, 716-727, doi: 10.2478/s11600-009-0011-z

Jaiswal, P., Dewangan, P., Ramprasad, T., et al., 2012. Seismic characterization of hydrates in faulted, fine-grained sediments of Krishna-Godavari basin: Unified imaging. J. Geophys. Res. 117, B04306, doi: 10.1029/2011jb009024

Jaiswal, P., Zelt, C.A., Dasgupta, R., et al., 2009. Seismic imaging of the Naga thrust using multiscale waveform inversion. Geophysics 74, WCC129-WCC140, doi: 10.1190/1.3158602

Jo, C.-H., Shin, C., Suh, J.H., 1996. An optimal 9-point, finite-difference, frequency-space, 2D scalar wave extrapolator. Geophysics 61, 529-537, doi: 10.1190/1.1443979

LeBlanca, C., Louden, K., Mosher, D., 2007. Gas hydrates off Eastern Canada: Velocity models from wide-angle seismic profiles on the Scotian Slope. Marine and Petroleum Geology 24, 321-335, doi: 10.1016/j.marpetgeo.2006.05.008

Lee, M.W., 2006. Is Amplitude Loss of Sonic Waveforms Due to Intrinsic Attenuation or Source Coupling to the Medium? Scientific Investigations Report, Reston, Virginia. 
Li, X., Zhong, L.R., Pyrak-Nolte, L.J., 2001. Physics of partially saturated porous media: Residual saturation and seismic-wave propagation. Annual Review of Earth and Planetary Sciences 29, 419-460, doi: 10.1146/annurev.earth.29.1.419

Liu, X., Flemings, P.B., 2006. Passing gas through the hydrate stability zone at southern Hydrate Ridge, offshore Oregon. Earth and Planetary Science Letters 241, 211-226, doi: 10.1016/j.epsl.2005.10.026

Marfurt, K.J., 1984. Accuracy of finite-difference and finite-element modeling of the scalar and elastic wave equations. Geophysics 49, 533-549, doi: 10.1190/1.1441689

Masson, Y.J., Pride, S.R., 2011. Seismic attenuation due to patchy saturation. Journal of Geophysical Research-Solid Earth 116, doi: 10.1029/2010jb007983

Max, M.D., 2003. Natural Gas Hydrate in Oceanic and Permafrost Environments. Kluwer Academic Publishers, AA Dortrecht.

Mora, P., 1987. Nonlinear two-dimensional elastic inversion of multioffset seismic data. Geophysics 52, 1211-1228, doi: 10.1190/1.1442384

Muller, T.M., Gurevich, B., 2004. One-dimensional random patchy saturation model for velocity and attenuation in porous rocks. Geophysics 69, 1166-1172, doi: 10.1190/1.1801934

Muller, T.M., Gurevich, B., Lebedev, M., 2010. Seismic wave attenuation and dispersion resulting from wave-induced flow in porous rocks - A review. Geophysics 75, 147-164, doi: 10.1190/1.3463417

Pecher, I.A., Henrys, S.A., Wood, W.T., et al., 2010. Focussed fluid flow on the Hikurangi Margin, New Zealand-Evidence from possible local upwarping of the base of gas hydrate stability. Marine Geology 272, 99-113, doi: 10.1016/j.margeo.2009.10.006

Pecher, I.A., Holbrook, W.S., 2000. Seismic methodologies for detecting and quantifying marine methane hydrate/free gas reservoirs. Kluwer Academic Publishers, Dordrecht.

Pecher, I.A., Minshull, T.A., Singh, S.C., et al., 1996. Velocity structure of a bottom simulating reflector offshore Peru: Results from full waveform inversion. Earth and Planetary Science Letters 139, 459-469, doi: 10.1016/0012-821x(95)00242-5

Petersen, C.J., Papenberg, C., Klaeschen, D., 2007. Local seismic quantification of gas hydrates and BSR characterization from multi-frequency OBS data at northern Hydrate Ridge. Earth and Planetary Science Letters 255, 414-431, doi: 10.1016/j.epsl.2007.01.002

Pratt, R.G., 1999. Seismic waveform inversion in the frequency domain, Part 1: Theory and verification in a physical scale model. Geophysics 64, 888-901, doi: 10.1190/1.1444597

Pratt, R.G., Worthington, M.H., 1990. Inverse-theory applied to multisource cross-hole tomography .1. Acoustic wave-equation method. Geophysical Prospecting 38, 287-310, doi: 10.1111/j.13652478.1990.tb01846.x 
Press, W.H., Teukolsky, S.A., Vetterling , W.T., et al., 1992. Numerical Recipes in C : the art of scientific computing, 2nd ed. University Press.

Priest, J.A., Best, A.I., Clayton, C.R.I., 2006. Attenuation of seismic waves in methane gas hydratebearing sand. Geophysical Journal International 164, 149-159, doi: 10.1111/j.1365-246X.2005.02831.X

Quintal, B., Steeb, H., Frehner, M., et al., 2011. Quasi-static finite element modeling of seismic attenuation and dispersion due to wave-induced fluid flow in poroelastic media. Journal of Geophysical Research-Solid Earth 116, doi: 10.1029/2010jb007475

Rempel, A.W., 2011. A model for the diffusive growth of hydrate saturation anomalies in layered sediments. J. Geophys. Res. in press, doi:10.1029/2011JB008484

Riedel, M., Collett, T.S., Kumar, P., et al., 2010. Seismic imaging of a fractured gas hydrate system in the Krishna-Godavari Basin offshore India. Marine and Petroleum Geology 27, 1476-1493, doi: 10.1016/j.marpetgeo.2010.06.002

Rossi, G., Gei, D., Bohm, G., et al., 2007. Attenuation tomography: An application to gas-hydrate and free-gas detection. Geophysical Prospecting 55, 655-669, doi: 10.1111/j.1365-2478.2007.00646.x

Schnurle, P., Liu, C.S., Hsiuan, T.H., et al., 2004. Characteristics of gas hydrate and free gas offshore southwestern Taiwan from a combined MCS/OBS data analysis. Marine Geophysical Researches 25, 157-180, doi: 10.1007/s11001-005-0740-6

Schowalter, T.T., 1979. Mechanics of secondary hydrocarbon migration and entrapment, AAPG Bulletin-American Association of Petroleum Geologists, pp. 723-760.

Shipley, T.H., Houston, M.H., Buffler, R.T., et al., 1979. Seismic evidence for widespread possible gas hydrate horizons on continental slopes and rises, Aapg Bulletin-American Association of Petroleum Geologists, pp. 2204-2213.

Singh, S.C., Minshull, T.A., Spence, G.D., 1993. Velocity structure of a gas hydrate reflector. Science 260, 204-207, doi: 10.1126/science.260.5105.204

Sirgue, L., Pratt, R.G., 2004. Efficient waveform inversion and imaging: A strategy for selecting temporal frequencies. Geophysics 69, 231-248, doi: 10.1190/1.1649391

Sultan, N., Riboulot, V., Ker, S., et al., 2011. Dynamics of fault-fluid-hydrate system around a shalecored anticline in deepwater Nigeria. Journal of Geophysical Research-Solid Earth 116, doi: B12110 10.1029/2011jb008218

Taylor, M.H., Dillon, W.P., Pecher, I.A., 2000. Trapping and migration of methane associated with the gas hydrate stability zone at the Blake Ridge Diapir: new insights from seismic data. Marine Geology 164, 79-89, doi: 10.1016/S0025-3227(99)00128-0

Toksoz, M.N., Johnston, D.H., Timur, A., 1979. Attenuation of seismic waves in dry and saturated rocks: I. Laboratory measurements. Geophysics 44, 681-690, doi: 
Virieux, J., Operto, S., 2009. An overview of full-waveform inversion in exploration geophysics. Geophysics 74, WCC1-WCC26, doi: 10.1190/1.3238367

Wang, X., Wu, S., Yuan, S., et al., 2010. Geophysical signatures associated with fluid flow and gas hydrate occurrence in a tectonically quiescent sequence, Qiongdongnan Basin, South China Sea. Geofluids 10, 351-368, doi: 10.1111/j.1468-8123.2010.00292.x

Westbrook, G.K., Chand, S., Rossi, G., et al., 2008. Estimation of gas hydrate concentration from multicomponent seismic data at sites on the continental margins of NW Svalbard and the Storegga region of Norway. Marine and Petroleum Geology 25, 744-758, doi: 10.1016/j.marpetgeo.2008.02.003

White, J.E., 1975. Computed seismic speeds and attenuation in rocks with partial gas saturation. Geophysics 40, 224-232, doi: 10.1190/1.1440520

Wood, W.T., Holbrook, S.W., Hoskins, H., 2000. In Situ Measurements of P-Wave Attenuation in the Methane Hydrate- and Gas-Bearing Sediments of the Blake Ridge, in: Paull, C.K., Matsumoto, R., Wallace, P.J., Dillon, W.P. (Eds.), Proc. ODP Sci. Results. Ocean Drilling Program, College Station, Texas.

Wu, R.-S., Toksoz, M.N., 1987. Diffraction tomography and multisource holography applied to seismic imaging. Geophysics 52, 11-25, doi: 10.1190/1.1442237

Xia, G.Y., Sen, M.K., Stoffa, P.L., 2000. Mapping of elastic properties of gas hydrates in the Carolina trough by waveform inversion. Geophysics 65, 735-744, doi: 10.1190/1.1444772

Zelt, C.A., 1999. Modelling strategies and model assessment for wide-angle seismic traveltime data. Geophysical Journal International 139, 183-204, doi: 10.1046/j.1365-246X.1999.00934.x

Zillmer, M., 2006. A method for determining gas-hydrate or free-gas saturation of porous media from seismic measurements. Geophysics 71, N21-N32, doi: 10.1190/1.2192910

Zillmer, M., Flueh, E.R., Petersen, J., 2005. Seismic investigation of a bottom simulating reflector and quantification of gas hydrate in the Black Sea. Geophysical Journal International 161, 662-678, doi: 10.1111/j.1365-246X.2005.02635.X 


\section{FIGURE CAPTIONS}

Figure 1. Base map. Seismic line used in this study is shown and graduated every $200^{\text {th }}$ CDP. Bathymetry contours are labeled every 50m. Location of sites NGHP-01-10, 12, and 13 with their projection on the seismic line are shown with solid black and white stars respectively. The sites are projected along the regional faults, F1 - 4, interpreted after Dewangan et al. (2011) in grey dashed lines. Location of the study area with respect to the Indian subcontinent is shown in the inset. Also shown in the inset is a comparison of the sonic log (in grey) from Site NGHP-01-10 with the stacking velocity (from Paper1; dashed blue), traveltime velocity (from Paper1; dashed red), and the waveform velocity (solid red) profiles at the projected location of Site NGHP-01-10 on the seismic line.

Figure 2. FWI $V_{\mathrm{P}}$ model evolution. (a) Starting model from Unified Imaging (Figure 3d; Paper1). Models in (b) through (g) are from successive inversion of $8.4-9.2 \mathrm{~Hz}, 9.6-10.4 \mathrm{~Hz}, 11.2-12.0 \mathrm{~Hz}$, $13.2-14.0 \mathrm{~Hz}, 15.6-16.4 \mathrm{~Hz}$, and $17.6 \mathrm{~Hz}-18.4 \mathrm{~Hz}$ respectively; model after inversion of 15.6 - 16.4 $\mathrm{Hz}$ is final. (h) Checkerboard test using the real data coverage, real bandwidth ( $8-16 \mathrm{~Hz}$ ), real time window, and (a) as the starting model. The checkerboard dimension and strength are $100 \mathrm{~m} \mathrm{X} \mathrm{30m} \mathrm{and}$ $10 \%$ respectively. Also shown are $1.7 \mathrm{~km} / \mathrm{s}$ and $1.4 \mathrm{~km} / \mathrm{s}$ velocity contours respectively representing the lower and upper limits of hydrate and free gas. The seafloor, the BSR, and site projections are labeled. Inverted triangles in (h) mark the extent of the data used for visual comparison in Figure 5. Last model is incorrectly labeled "f" instead of "h".

Figure 3. FWI Qp model evolution. A starting model with zero attenuation is used. Models in (a) through (f) are from successive inversion of $8.4-9.2 \mathrm{~Hz}, 9.6-10.4 \mathrm{~Hz}, 11.2-12.0 \mathrm{~Hz}, 13.2-14.0 \mathrm{~Hz}, 15.6$ 16.4 Hz, and $17.6 \mathrm{~Hz}-18.4 \mathrm{~Hz}$ respectively; model after inversion of $15.6-16.4 \mathrm{~Hz}$ is final. (g) Checkerboard test using the real data coverage, real bandwidth $(8-16 \mathrm{~Hz})$ and real time window. The velocity model used for $Q_{P}$ inversion is the final model from $V_{P}$ inversion (Figure 2f). The checkerboard dimension and strength are $100 \mathrm{~m}$ X 30m and $10 \%$ respectively. Poorly resolved zone is outlined with a dotted line. The seafloor, the BSR, and site projections are labeled. Inverted triangles in (g) mark the extent of the data used for visual comparison in Figure 5. 
Figure 4. Amplitude comparison. Absolute error (percentage) in the seafloor reflection amplitudes between (a) the real and simulated data from the starting model (Figure 2a); (b) real and simulated data from the final $V_{P}$ model (Figure 2f); and (c) real and simulated data from the final $V_{P}$ and $Q_{P}$ model (Figures $2 \mathrm{f}$ and 3e). Absolute error (percentage) in the RMS amplitudes of the whole reflection coda between (d) the real and simulated data from the starting model (Figure 2a); (e) real and simulated data from the final $V_{P}$ model (Figure 2f); and (f) real and simulated data from the final $V_{P}$ and $Q_{P}$ model (Figures $2 \mathrm{f}$ and $3 e$ ). Seafloor bathymetry is displayed on top along with the projection of sites NGHP01-10-13.

Figure 5. Data comparison. (a) real data, (b) simulated data using the initial model (Figure 2a), (c) simulated data from the final $V_{P}$ model (Figure 2f), and (d) simulated data from the final $V_{P}$ and $Q_{P}$ model (Figures $2 \mathrm{f}$ and 3e). The extent of the data is indicated in Figures 2 and 3. Dashed yellow boxes in (a) indicate zones of high trace-to-trace amplitude variation. Reflection arrival from the seafloor and a deeper reflection is picked in the real data with red and green dashed lines respectively and overlaid on the synthetic gathers. A close match between real and synthetic arrival times validates the fidelity of the initial and final models.

Figure 6. Composite interpretation. (a) Depth-migrated image. (b) $V_{P}$ (Figure 2f) and reflectivity (Figure 4d in Paper1) overlay. $V_{P}$ greater than $1.7 \mathrm{~km} / \mathrm{s}$ represents hydrates and less than $1.4 \mathrm{~km} / \mathrm{s}$ represents free gas. High amplitude horizons $\mathrm{H} 1$ and $\mathrm{H} 2$ are labeled. The seismic blank zone is outlined in dashed line. (c) $\mathrm{Q}_{\mathrm{P}}{ }^{-1}$ (Figure 3e) and fault structure (Figure 6b in Paper1) overlay. (d) $V_{P}$ and $Q_{P}$ overlay. In general, high $(>1.7 \mathrm{~km} / \mathrm{s}) \mathrm{V}_{\mathrm{P}}$ can be correlated with low $\mathrm{Q}_{\mathrm{P}}{ }^{-1}$ zones suggesting that hydrates may reduce attenuation. In (b) - (d), the BSR is interpreted after Paper1 and the projected sites NGHP-01-10 - 13 are labeled. 


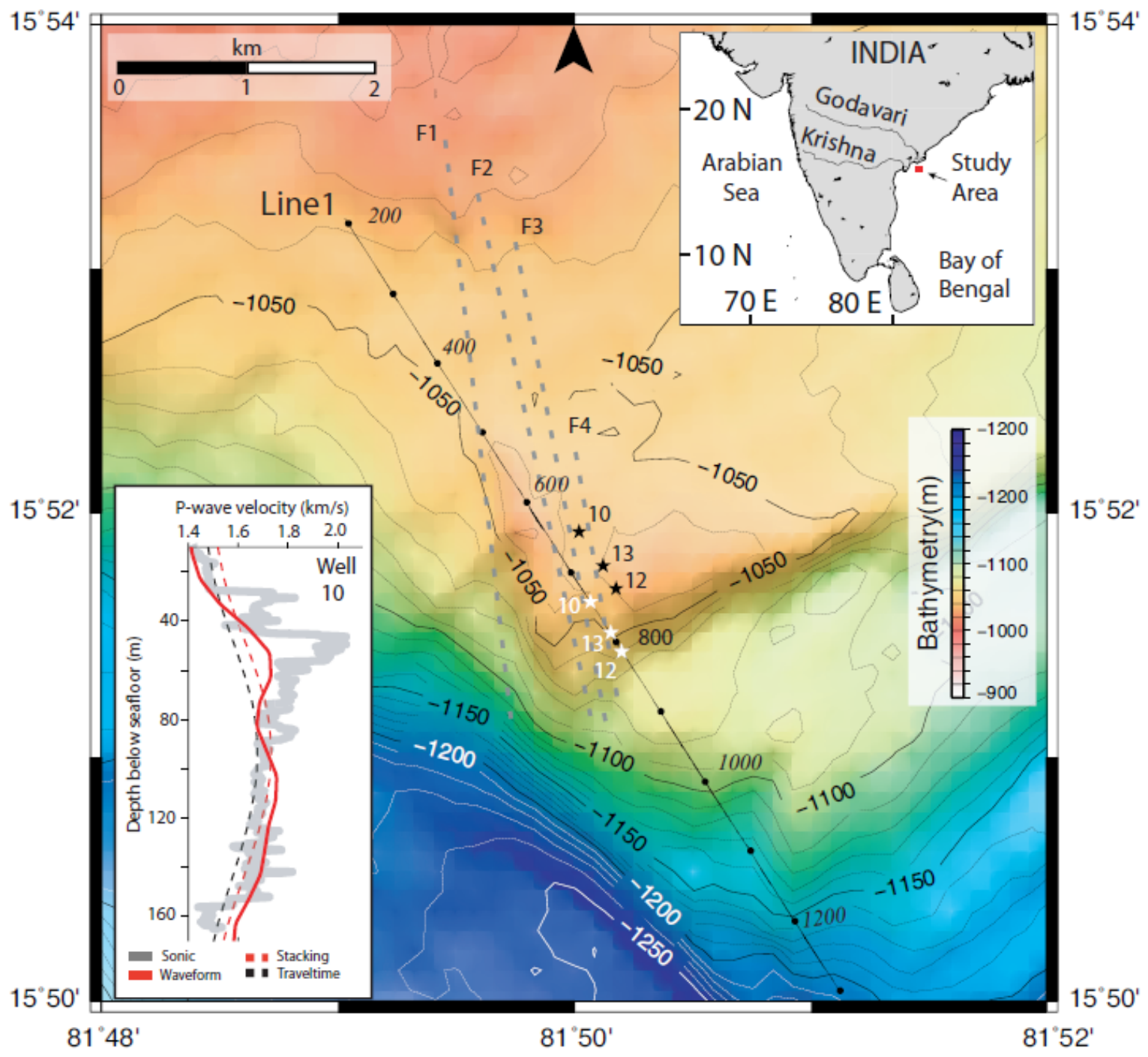

Figure 1. Base map. Seismic line used in this study is shown and graduated every 200th CDP. Bathymetry contours are labeled every 50m. Location of sites NGHP-01-10, 12, and 13 with their projection on the seismic line are shown with solid black and white stars respectively. The sites are projected along the regional faults, F1 - 4, interpreted after Dewangan et al. (2011) in grey dashed lines. Location of the study area with respect to the Indian subcontinent is shown in the inset. Also shown in the inset is a comparison of the sonic log (in grey) from Site NGHP-01-10 with the stacking velocity (from Paper1; dashed blue), traveltime velocity (from Paper1; dashed red), and the waveform velocity (solid red) profiles at the projected location of Site NGHP-01-10 on the seismic line. 


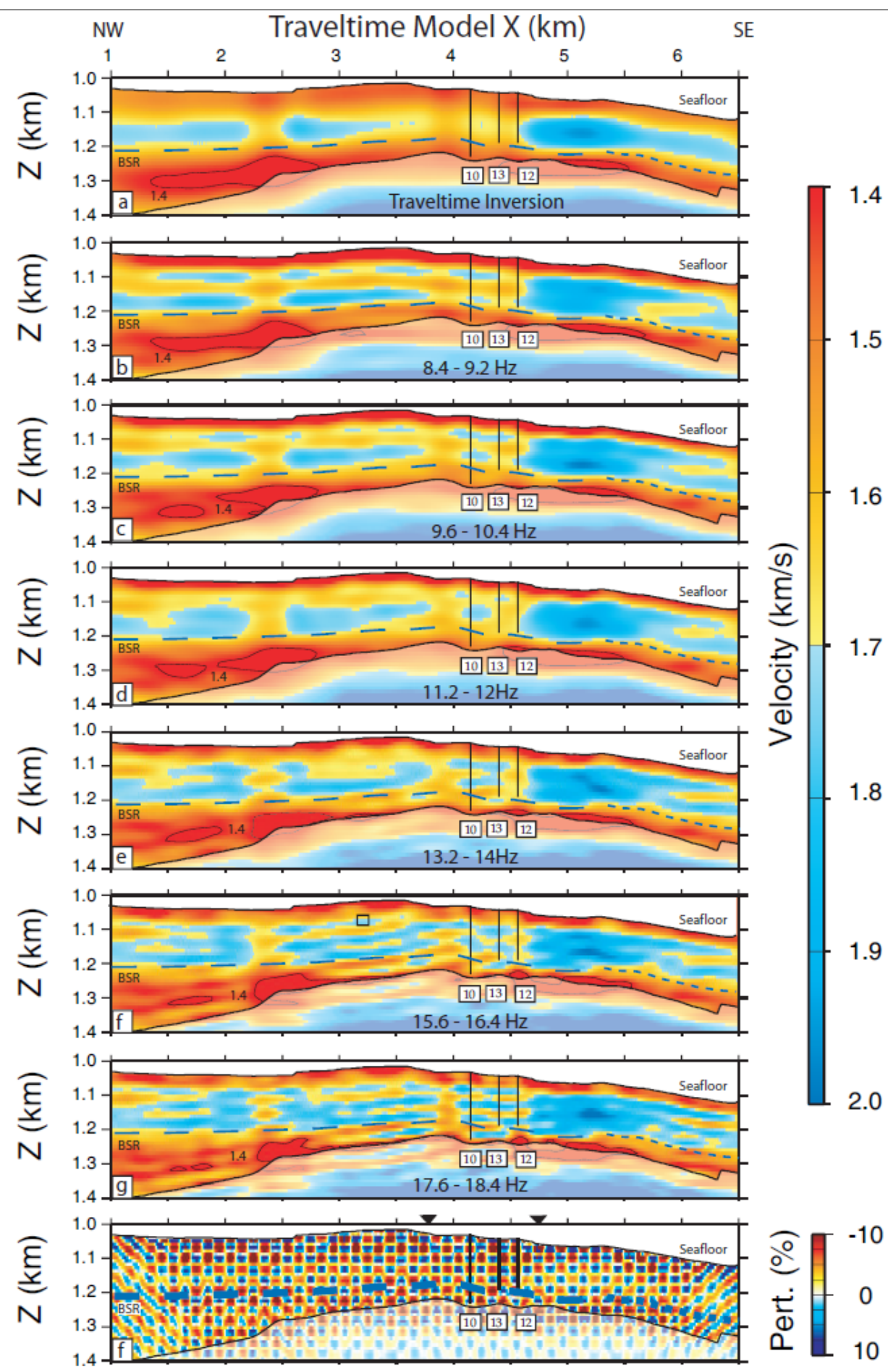

Figure 2.FWI VP model evolution. (a) Starting model from Unified Imaging (Figure 3d; Paper1). Models in (b) through (g) are from successive inversion of $8.4-9.2 \mathrm{~Hz}, 9.6-10.4 \mathrm{~Hz}, 11.2-12.0 \mathrm{~Hz}, 13.2-14.0 \mathrm{~Hz}, 15.6-16.4 \mathrm{~Hz}$, and $17.6 \mathrm{~Hz}-18.4 \mathrm{~Hz}$ respectively; model after inversion of $15.6-16.4 \mathrm{~Hz}$ is final. (h) Checkerboard test using the real data coverage, real bandwidth $(8-16 \mathrm{~Hz})$, real time window, and (a) as the starting model. The checkerboard dimension and strength are $100 \mathrm{~m} \mathrm{X30m}$ and $10 \%$ respectively. Also shown are $1.7 \mathrm{~km} / \mathrm{s}$ and $1.4 \mathrm{~km} / \mathrm{s}$ velocity contours respectively representing the lower and upper limits of hydrate and free gas. The seafloor, the BSR, and site projections are labeled. Inverted triangles in (h) mark the extent of the data used for visual comparison in Figure 5. Last model is incorrectly labeled "f" instead of " $\mathrm{h}$ ". 


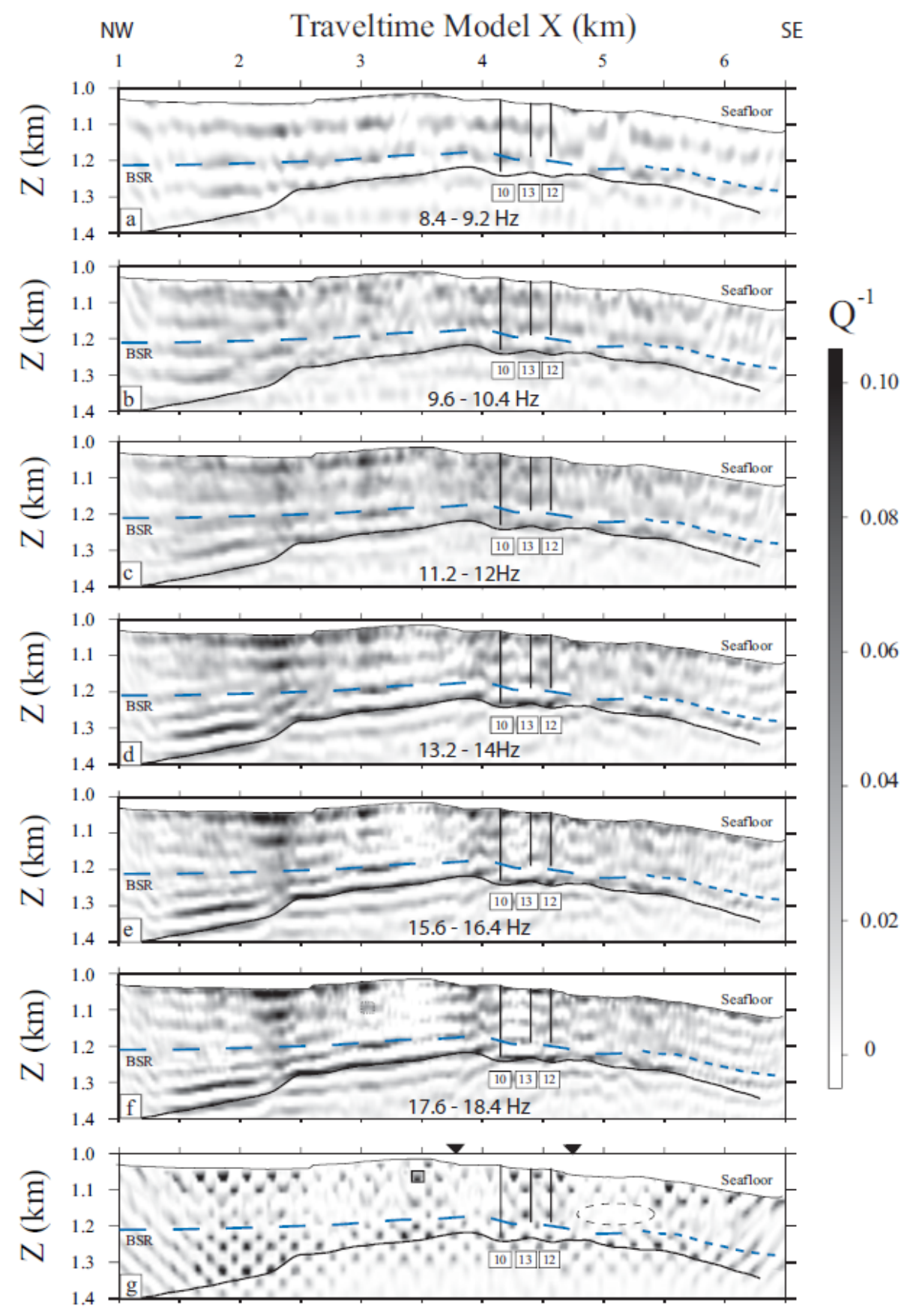

Figure 3. FWI QP model evolution. A starting model with zero attenuation is used. Models in (a) through (f) are from successive inversion of $8.4-9.2 \mathrm{~Hz}, 9.6-10.4 \mathrm{~Hz}, 11.2-12.0 \mathrm{~Hz}, 13.2-14.0 \mathrm{~Hz}, 15.6-16.4 \mathrm{~Hz}$, and $17.6 \mathrm{~Hz}$ $-18.4 \mathrm{~Hz}$ respectively; model after inversion of $15.6-16.4 \mathrm{~Hz}$ is final. $(\mathrm{g})$ Checkerboard test using the real data coverage, real bandwidth $(8-16 \mathrm{~Hz})$ and real time window. The velocity model used for QP inversion is the final model from VP inversion (Figure 2f). The checkerboard dimension and strength are $100 \mathrm{~m} X 30 \mathrm{~m}$ and $10 \%$ respectively. Poorly resolved zone is outlined with a dotted line. The seafloor, the BSR, and site projections are labeled. Inverted triangles in (g) mark the extent of the data used for visual comparison in Figure 5. 

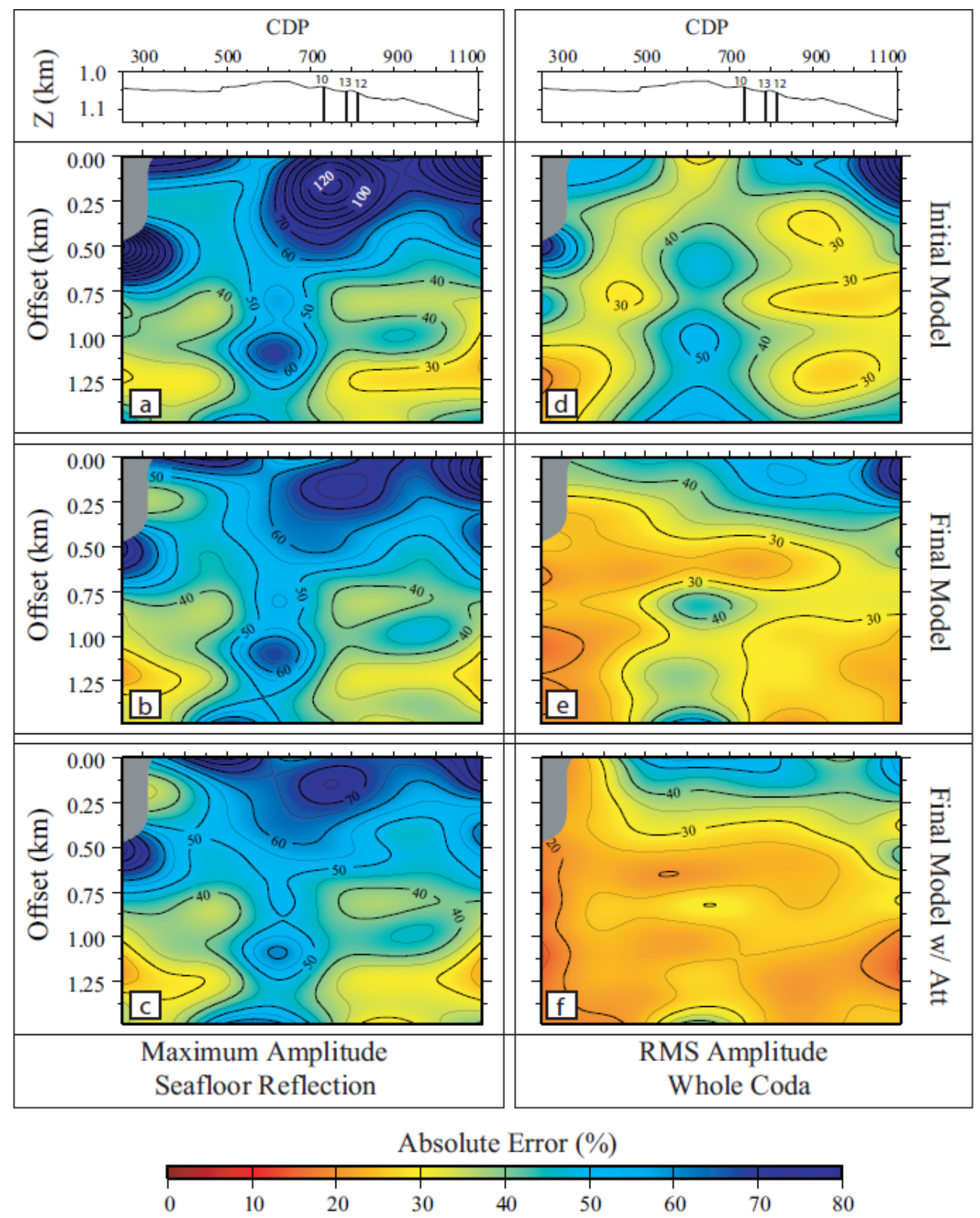

Figure 4. Amplitude comparison. Absolute error (percentage) in the seafloor reflection amplitudes between (a) the real and simulated data from the starting model (Figure 2a); (b) real and simulated data from the final VP model (Figure 2f); and (c) real and simulated data from the final VP and QP model (Figures $2 \mathrm{f}$ and $3 \mathrm{e}$ ). Absolute error (percentage) in the RMS amplitudes of the whole reflection coda between (d) the real and simulated data from the starting model (Figure 2a); (e) real and simulated data from the final VP model (Figure 2f); and (f) real and simulated data from the final VP and QP model (Figures $2 \mathrm{f}$ and $3 \mathrm{e}$ ). Seafloor bathymetry is displayed on top along with the projection of sites NGHP-01-10 - 13. 

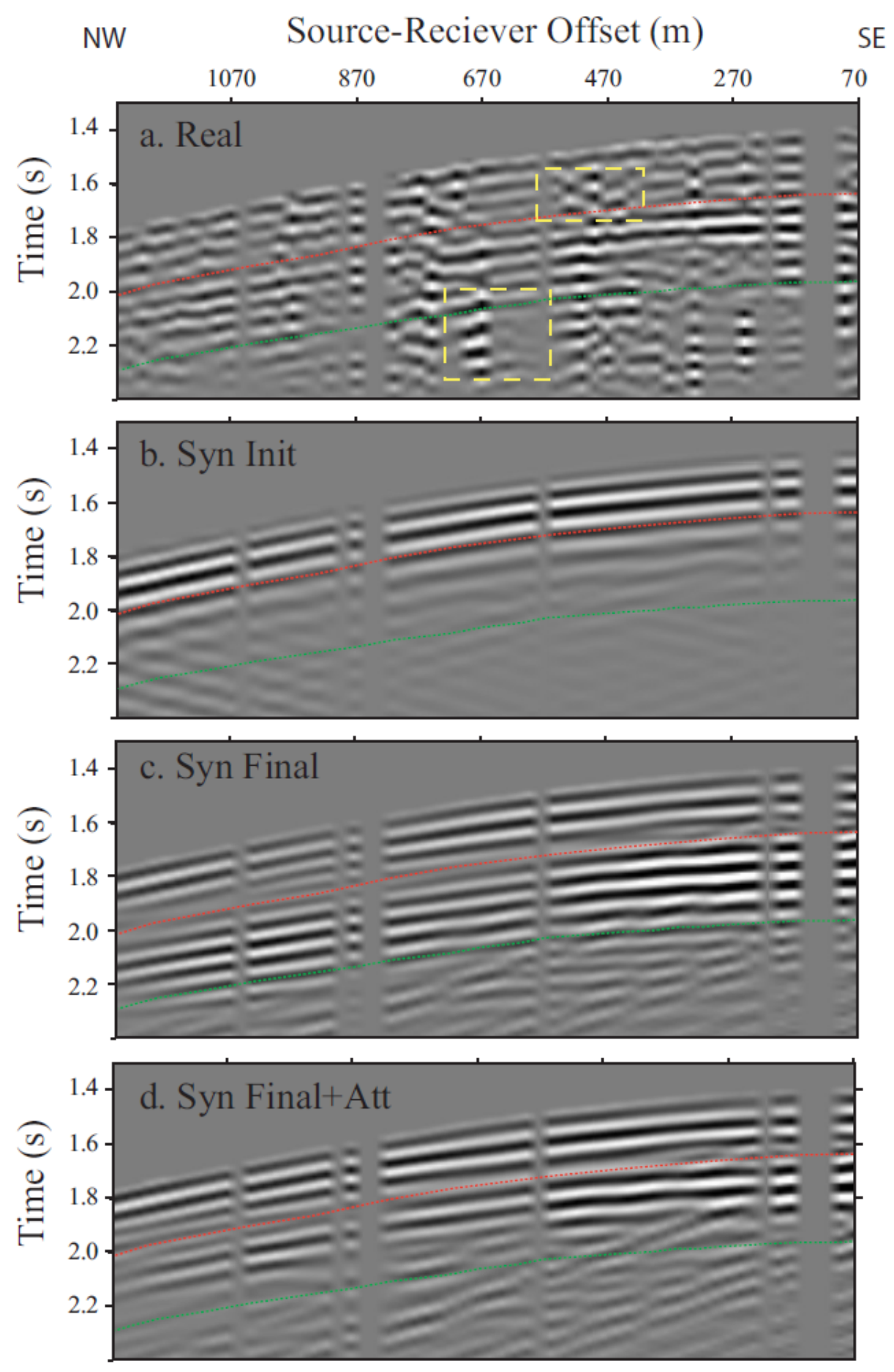

Figure 5. Data comparison. (a) real data, (b) simulated data using the initial model (Figure 2a), (c) simulated data from the final VP model (Figure 2f), and (d) simulated data from the final VP and QP model (Figures $2 \mathrm{f}$ and 3e). The extent of the data is indicated in Figures 2 and 3. Dashed yellow boxes in (a) indicate zones of high trace-to-trace amplitude variation. Reflection arrival from the seafloor and a deeper reflection is picked in the real data with red and green dashed lines respectively and overlaid on the synthetic gathers. A close match between real and synthetic arrival times validates the fidelity of the initial and final models. 

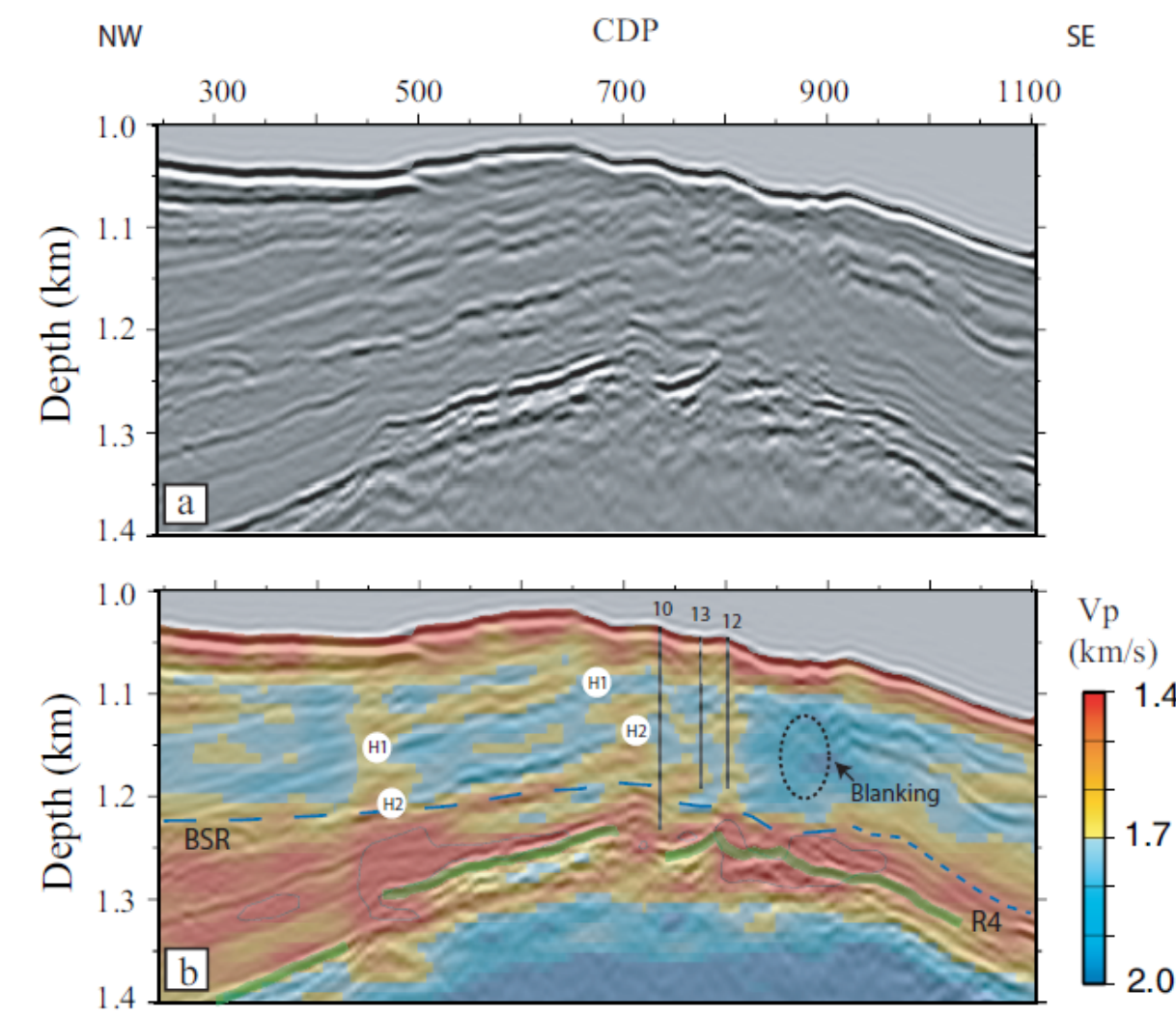

SE
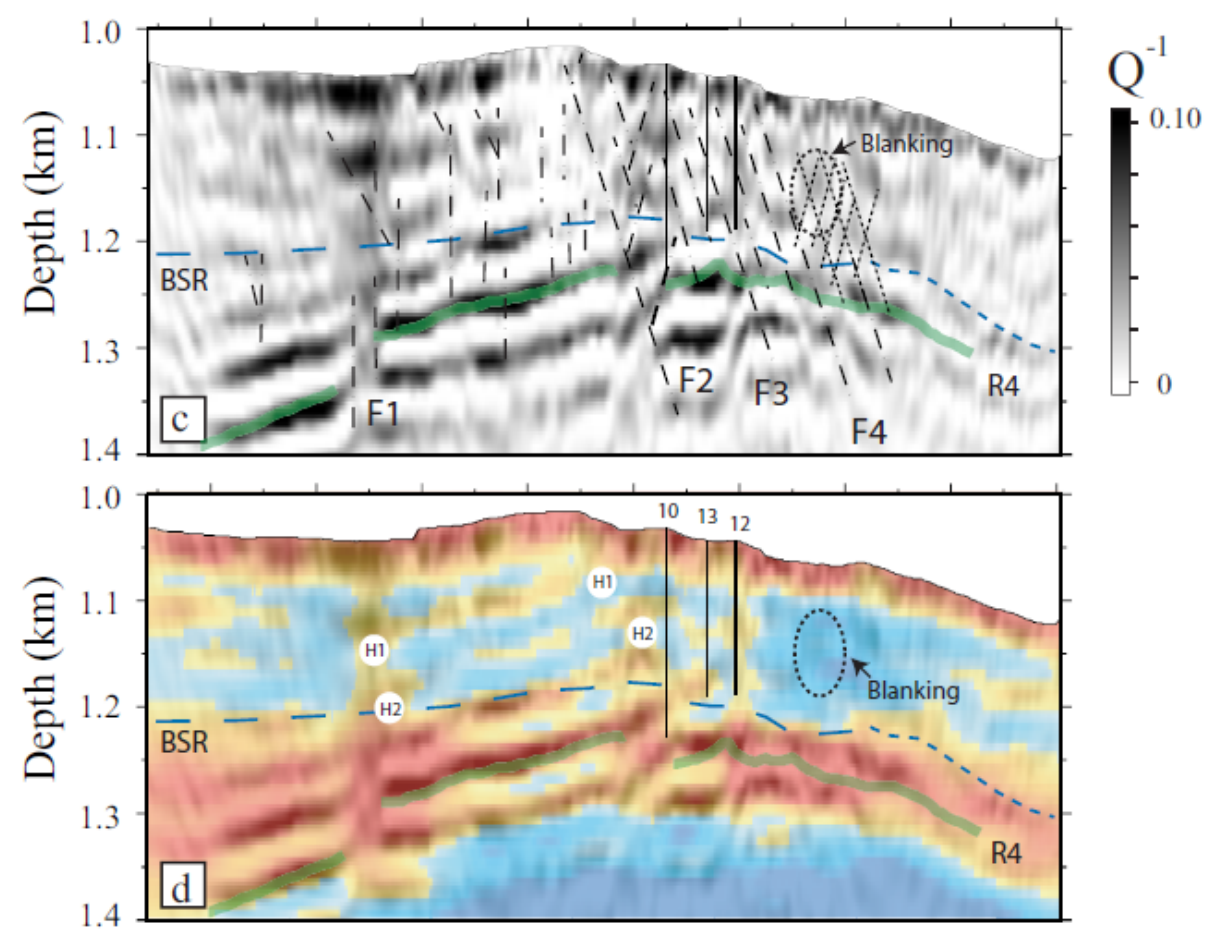

Figure 6.Composite interpretation. (a) Depth-migrated image. (b) VP (Figure 2f) and reflectivity (Figure 4d in Paper1) overlay. VP greater than $1.7 \mathrm{~km} / \mathrm{s}$ represents hydrates and less than $1.4 \mathrm{~km} / \mathrm{s}$ represents free gas. High amplitude horizons $\mathrm{H} 1$ and $\mathrm{H} 2$ are labeled. The seismic blank zone is outlined in dashed line. (c) QP-1 (Figure 3e) and fault structure (Figure 6b in Paper1) overlay. (d) VP and QP overlay. In general, high (>1.7 km/s) VP can be correlated with low QP-1 zones suggesting that hydrates may reduce attenuation. In (b) - (d), the BSR is interpreted after Paper1 and the projected sites NGHP-01-10 - 13 are labeled. 